\title{
Calcium in milk and fermentation by yoghurt bacteria increase the resistance of rats to salmonella infection
}

\author{
I Bovee-Oudenhoven, D Termont, R Dekker, R Van der Meer
}

\begin{abstract}
Calcium in milk products stimulates gastric acid secretion and inhibits the cytolytic activity of intestinal contents. Based on these effects, it was hypothesised that calcium might lessen the severity of food borne intestinal infections. The possible differential effects of a low calcium milk and normal milk products (milk, acidified milk, and pasteurised yoghurt) on the resistance of rats to a salmonella infection was therefore studied. Rats were infected orally with Salmonella enteritidis just after food consumption. The first day after infection, faecal salmonella counts of the yoghurt fed rats were significantly lower than those of the other groups. Thereafter, faecal salmonella excretion declined rapidly in all high calcium groups, whereas rats fed the low calcium milk continued to excrete high numbers of salmonella. The reduced colonisation resistance to salmonella of rats fed low calcium milk might be caused by the high cytolytic activity of faecal water or a high iron concentration in faecal water, already present before infection, or both. The reduced resistance of these rats corresponded with a large infection induced increase in the cytolytic activity of faecal water, an appreciable reduction in apparent iron absorption, and a large increase in faecal mucin and alkaline phosphatase excretion. In yoghurt fed rats, only minor infection induced changes in luminal parameters were noticed. The rats fed milk and acidified milk always showed intermediate reactions. In conclusion, in addition to fermentation by yoghurt bacteria, calcium in milk products strongly enhanced the resistance to salmonella infection by lowering luminal cytolytic activity or diminishing the availability of iron for pathogen growth, or both.
\end{abstract}

(Gut 1996; 38: 59-65)

Keywords: rats, Salmonella enteritidis infection, increased resistance, calcium, yoghurt.

The first defence mechanism of host resistance to gastrointestinal infections is the gastric barrier. ${ }^{1}$ Pathogens, for instance Salmonella sp, introduced into the stomach are effectively destroyed by gastric acid. ${ }^{2-4}$ The interaction of gastric acid and ingested bacteria is conditioned by other variables in addition to gastric acid secretion, namely physical protection of bacteria by food, buffering of gastric content, and rate of gastric emptying. The effectiveness of the gastric barrier can be influenced by milk products. By stimulating gastrin release, calcium in milk products induces gastric acid secretion. ${ }^{56}$ In addition, the gastric emptying rate of fermented milk is half that of milk, ${ }^{7}$ so simultaneously ingested pathogens have to endure a prolonged exposure to gastric acid as well as to lactic acid in the fermented milk. Beyond the gastric barrier, a second line of non-immunological defence mechanisms is situated in the intestine. Antibacterial effects of bile acids and pancreatic enzymes, the motility of the intestine, normal epithelial cell turnover, the presence of an autochthonous microflora, and intestinal mucin secretion, act together to eliminate harmful exogenous bacteria. ${ }^{1}$ Many of these intestinal parameters are influenced by diet. ${ }^{8-11}$ For instance, calcium in milk products inhibits the cell damaging activity of intestinal contents and decreases epithelial cell proliferation by precipitating bile acids among others. ${ }^{11-14}$

Considering the above mentioned effects of calcium on gastric acid secretion and the intestinal epithelium, the question arises whether calcium in milk products increases resistance to food borne infections. To address that question, we performed a strictly controlled infection experiment in which we compared the resistance to a salmonella infection of rats fed a low calcium milk, regular milk, milk acidified with hydrochloric acid, or pasteurised yoghurt.

\section{Methods}

\section{ANIMALS, DIETS, AND INFECTION}

The experimental protocol was approved by the animal welfare officer of the Agricultural University, Wageningen, The Netherlands. Specific pathogen free, male Wistar rats (WU, Harlan, Zeist, The Netherlands), aged 10 weeks and with a mean body weight of about $330 \mathrm{~g}$, were housed individually ( $\mathrm{n}=9$ per diet) in metabolic cages in a room with controlled temperature $\left(22-24^{\circ} \mathrm{C}\right)$, relative humidity $(50-60 \%)$, and light/dark cycle (light, 6.00-18.00 hours).

The experimental milk products were manufactured by the Technology Department of our institute. Because rats are lactose intolerant, the milk $3.7 \%$ fat, $3.0 \%$ protein, $30 \mathrm{mmol}$ calcium $/ \mathrm{l}$ ) and low calcium milk
Dr R Van der Meer,

Department of Nutrition

Dairy Research, PO Box 20

NL-6710 BA Ede, The

Netherlands.

Accepted for publication 12 July 1995 
(Calcinon, Nutricia, Zoetermeer, The Netherlands, $3 \cdot 8 \%$ fat, $3 \cdot 1 \%$ protein; $\mathrm{CaCO}_{3}$ was added to obtain $6 \mathrm{mmol}$ calcium $/ \mathrm{l}$ ) were first treated with lactase (Maxilact LX5000, Gist-brocades, Delft, The Netherlands). Sugar determination of the lactase treated products by HPLC analysis ${ }^{15}$ showed complete hydrolysis of lactose. Thereafter the low calcium milk and part of the normal milk were sterilised ( 15 seconds at $140^{\circ} \mathrm{C}$ ) and bottled aseptically. Yoghurt was prepared from the (lactase treated) regular milk by standard procedures, using cultures of Lactobacillus bulgaricus and Streptococcus thermophilus. The yoghurt was homogenised, pasteurised (15 seconds at $74^{\circ} \mathrm{C}$ ), and bottled aseptically. The milk products were stored at $4^{\circ} \mathrm{C}$ until use. Acidified milk was prepared by acidifying (lactase treated) regular milk with concentrated hydrochloric acid to $\mathrm{pH} 4 \cdot 2$, which was the $\mathrm{pH}$ of the yoghurt. For animal food preparation, $125 \mathrm{~g}$ of rice flour (Molenaar, Milupa BV, Amersfoort, The Netherlands), $20 \mathrm{~g}$ cellulose, vitamins, ${ }^{16}$ and $0 \cdot 1 \mathrm{mmol}$ ferric citrate $(\mathrm{BDH}$ Chemicals Ltd, Poole, England) were added to 1 litre of milk product. The dry weight percentage of these animal foods was $23 \cdot 3 \%$. Food was prepared freshly every three days and stored at $4^{\circ} \mathrm{C}$. The food racks of the animals were changed every day. Food and demineralised drinking water were supplied ad libitum. Food intake was recorded every day and body weight every three days.

Animals were acclimatised to the housing and dietary conditions for nine days, after which they were infected with Salmonella enteritidis (clinical isolate, phage type 1), which is an increasingly important food pathogen. ${ }^{17}$ Details of the kinetics of a salmonella infection in rodents ${ }^{3}$ and the properties and maintenance of this pathogen ${ }^{18}$ are described elsewhere. Before infection, the rats were starved overnight. At 9.00 am the next day food was supplied ad libitum. At 11.00 am all rats were infected orally by gastric gavage with $1 \mathrm{ml}$ of saline containing $1 \cdot 10^{9}$ viable $S$ enteritidis. The exact viable counts of $S$ enteritidis in the inoculum were determined by plating on Brilliant Green Agar (Oxoid, Basingstoke, England). Before, and on days 1, 5, and 12 after salmonella infection, fresh individual faecal samples were collected. The number of salmonella in faeces was quantified by plating on Modified Brilliant Green Agar (Oxoid) supplemented with sulphamandelate (Oxoid) as described and validated by Giaffer et al. ${ }^{19}$

\section{TOTAL FAECES ANALYSES}

Faeces were quantitatively collected two days before salmonella infection and on days 5 and 6 after infection. Faeces were freeze dried for dry weight determination. After dry ashing and destruction $\left(15\right.$ minutes at $\left.180^{\circ} \mathrm{C}\right)$ with a perchloric acid $(70 \%)$ /hydrogen peroxide $(30 \%)$ mixture $(3: 1 \mathrm{v} / \mathrm{v})$ of freeze dried faeces, iron was measured using an atomic absorption spectrophotometer (Model 1100, Perkin Elmer Corp, Norwalk, USA). Inorganic phosphate was extracted from freeze dried faeces with $5 \%(\mathrm{w} / \mathrm{v})$ trichloroacetic acid and measured according to the method of Fiske and Subbarow. ${ }^{20}$ Total bile acids were extracted from freeze dried faeces with a t-butanol/water mixture $(1: 1 \mathrm{v} / \mathrm{v})$ as described previously. ${ }^{21}$ Extracts were assayed for bile acids using a fluorimetric enzymatic assay. ${ }^{22}$ For mucin determination, freeze dried faeces were suspended in 20 volumes of phosphate buffered saline, mixed, and immediately incubated in a shaking waterbath at $95^{\circ} \mathrm{C}$ for 10 minutes to denature glycosidases. Control experiments showed no degradation of purified mucin (crude porcine stomach mucin; Sigma, St Louis, USA) during this heat treatment. Thereafter, mucins were solubilised by incubating for 90 minutes at $37^{\circ} \mathrm{C}$. After centrifugation for 1 minute at $15000 \mathrm{~g}$ (Eppendorf 5415), mucins were measured using a fluorimetric assay that discriminates O-linked glycoproteins (mucins) from $\mathrm{N}$ linked glycoproteins. ${ }^{23}$ Standard solutions of $\mathrm{N}$-acetylgalactosamine (Sigma) were used to calculate the amount of oligosaccharides liberated from mucins during the procedure. The recovery of porcine stomach mucin added to dry faeces varied between 95 and $105 \%$. For alkaline phosphatase (ALP) determination, 30 $\mathrm{mg}$ of freeze dried faeces were suspended in 5 $\mathrm{ml}$ saline. After homogenisation, the suspensions were centrifuged for 5 minutes at $1500 \mathrm{~g}$ (Heraeus, Boom BV, Meppel, The Netherlands). ALP activity in the supernatants was determined spectrophotometrically as described elsewhere, ${ }^{13}$ except that inhibition with L-phenylalanine was omitted. In our earlier studies, ${ }^{11-14}$ inhibition of the intestinal isoenzyme with L-phenylalanine was used to quantify the contribution of bacterial ALP to total ALP activity. However, we now performed control experiments with faeces from germ free and conventional rats, which showed that the remaining activity in the presence of L-phenylalanine was exactly the same for both faeces $(10 \%$ of total ALP activity, data not shown).

FAECAL WATER ANALYSES

Faecal water was prepared by adding double distilled water to freeze dried faeces to obtain $35 \%$ dry weight, which mimics the conditions in the colon. Individual deviations of the mean dry weight percentage were proportionally corrected for. After homogenising, the samples were mixed regularly while incubated in a shaking waterbath $\left(1\right.$ hour at $\left.37^{\circ} \mathrm{C}\right)$, followed by centrifugation for 20 minutes at $12000 \mathrm{~g}$ (Hettich, Micro-rapid 1306, Tuttlingen, Germany). The aspirated supernatant was centrifuged for 2 minutes at $14000 \mathrm{~g}$ (Eppendorf 5415). After determination of the $\mathrm{pH}$ of the supernatants at $37^{\circ} \mathrm{C}$, faecal water was stored at $-20^{\circ} \mathrm{C}$ until further use.

For determination of cytolytic activity, human erythrocytes $(20 \mu l$ of a $25 \%$ haematocrit suspension) were mixed with 80 $\mu l$ of faecal water or $40 \mu$ faecal water plus 40 $\mu l$ saline. Before addition to the erythrocytes, the faecal waters were warmed to $37^{\circ} \mathrm{C}$. 
Effects of diets and salmonella infection on total faecal output and faecal inorganic phosphate excretion (values, mean (SEM))

\begin{tabular}{|c|c|c|c|c|c|}
\hline Diet & Infection & $\begin{array}{l}\text { Faecal wet weight } \\
(g / d)\end{array}$ & $\begin{array}{l}\text { Faecal dry weight } \\
(g / d)\end{array}$ & $\begin{array}{l}\text { Faecal dry/wet ratio } \\
(\%)\end{array}$ & $\begin{array}{l}\text { Faecal inorganic } P \\
(\mu \mathrm{mol} / \mathrm{d})\end{array}$ \\
\hline Low calcium milk & $\begin{array}{l}\text { Before } \\
\text { After }\end{array}$ & $\begin{array}{l}2.34(0.14)^{\star} \\
3.56(0.12) \dagger\end{array}$ & $\begin{array}{l}1.31(0.08)^{\star} \\
1.68(0.04) \dagger\end{array}$ & $\begin{array}{l}56(2)^{\star} \\
47(2)^{\star}\end{array}$ & $36(6)^{\star}$ \\
\hline \multirow[t]{2}{*}{ Milk } & Before & $2.49(0.19)^{\star}$ & $1.48(0.09)^{\star}$ & $60(1)^{\star}$ & $\begin{array}{l}02(4) T \\
407(25) \ddagger\end{array}$ \\
\hline & After & $3.51(0.24) \dagger$ & $1.95(0.12) \dagger$ & $56(2)^{\star}$ & $513(33) \S$ \\
\hline \multirow[t]{2}{*}{ Acidified milk } & Before & $2.35(0.16)^{\star}$ & $1.39(0.09)^{\star}$ & $59(1)^{\star}$ & $346(23) \ddagger^{\pi}$ \\
\hline & After & $3.33(0.34) \dagger$ & $1.89(0.18) \dagger$ & $58(2)^{\star}$ & $437(43) \neq \delta$ \\
\hline \multirow[t]{2}{*}{ Yoghurt } & Before & $2.29(0.15)^{\star}$ & $1.40(0.08)^{\star}$ & $60(1)^{\star}$ & $317(16)^{\pi}$ \\
\hline & After & $3.54(0.32) \dagger$ & $1.98(0.17) \dagger$ & $56(2)^{\star}$ & $440(30) \neq \varnothing$ \\
\hline
\end{tabular}

Values in the same column not sharing the same symbol are significantly different $(p<0.05)$.

Mixtures were incubated for 2 hours at $37^{\circ} \mathrm{C}$ in a shaking water bath. The intact erythrocytes in the pellet were washed three times with saline (centrifugation, 1 minute at $1500 \mathrm{~g}$ (Eppendorf 5415)). After lysing the erythrocytes in the pellet with double distilled water, trichloroacetic acid (final $5 \% \mathrm{w} / \mathrm{v}$ ) was added, followed by centrifugation for 1 minute at $14000 \mathrm{~g}$ (Eppendorf 5415). The potassium content of the supernatant was measured by atomic emission spectrophotometry (Model 1100, Perkin Elmer). Simultaneously, erythrocytes were incubated in saline $(0 \%$ haemolysis, corresponding to $100 \%$ potassium release) and in double distilled water $(100 \%$ haemolysis, corresponding to $0 \%$ potassium release). The percentage haemolysis was calculated from these $0 \%$ and $100 \%$ controls. The relevance and validation of this haemolysis assay is described elsewhere. ${ }^{24}$ Iron was measured in saline diluted, faecal water using an atomic absorption spectrophotometer (Model 1100, Perkin Elmer)

Bile acid determination in samples taken before infection was performed directly in diluted faecal water as described elsewhere. ${ }^{22}$ In contrast to pre-infection samples, the recovery of cholic acid added to post-infection samples was often poor, indicating that faecal water components interfered with the enzymatic assay. Therefore an alternative procedure was carried out as follows; post-infection samples were acidified (final $1 \mathrm{M} \mathrm{HCl}$ ) and subsequently extracted three times with diethyl ether. After evaporation of diethyl ether, the residue was resolubilised in methanol. This solution was hydrolysed in $80 \%(\mathrm{v} / \mathrm{v})$ methanol and $1 \mathrm{M} \mathrm{NaOH}$ for 1 hour at $80^{\circ} \mathrm{C}$. After evaporation of methanol and subsequent acidification with $\mathrm{HCl}$ (final $1 \mathrm{M}$ ), bile acids were again extracted with diethyl ether. After evaporation of diethyl ether, bile acids were resolublised in methanol and measured as described above. Using this procedure, the recovery of a mixture of cholic acid/deoxycholic acid/lithocholic acid (4:3:1) added to faecal water always exceeded $90 \%$. Control experiments showed that the bile acid concentration in faecal waters of the pre-infection period was identical when using the direct or the alternative procedure. Free fatty acids were analysed by gas chromatography as described earlier. ${ }^{14}$

STATISTICS

Results are presented as mean (SEM), with $\mathrm{n}=8$ for the yoghurt group and $\mathrm{n}=9$ for the other groups. Within one dietary group, differences between the mean values before and after infection were tested by Student's $t$ test for paired samples (two sided). Within one period, differences between diet groups were tested on their significance, using analysis of variance (ANOVA). In addition, Fisher's protected least significant difference test (two sided), modified for multiple comparisons, was used to identify dietary groups that differed from each other. The level of significance was preset at $p<0.05$. A commercially available statistical package was used for all statistics (SPSS/PC+ version 2.0, SPSS Inc, Chicago, USA).

\section{Results}

ANIMALS, FOOD INTAKE AND FAECAL OUTPUT The data from one animal in the yoghurt group were excluded from the study results because of oropharyngeal reflux of the $S$ enteritidis suspension which resulted in pneumonia. Food intake (mean $18 \mathrm{~g}$ dry weight per day) and body weight gain (mean $3 \mathrm{~g}$ per day) were not significantly affected by the different diets or the infection. Before the infection, the wet and dry faecal outputs did not differ between diet groups, nor did the percentage dry weight (Table). After infection, wet and dry faecal output increased significantly in all groups. In addition, the dry weight percentage of the faeces of animals fed the low calcium milk was significantly less compared with the other groups.

\section{COLONISATION RESISTANCE}

The first day after salmonella infection, rats fed yoghurt had a significantly lower salmonella excretion in faeces than rats fed the other diets (Fig 1). On day 5, population levels of salmonella in faeces were decreased noticeably in the high calcium diet groups. In contrast, rats fed the low calcium milk continued to excrete high salmonella levels in their faeces. This was also the case on day 12 after infection. Thus, rats fed the low calcium milk had a much lower colonisation resistance to salmonella than rats fed the high calcium diets.

\section{CYTOLYTIC ACTIVITY OF FAECAL WATER}

The $\mathrm{pH}$ of faecal water of the yoghurt group $(6.54(0.06))$ was higher $(p<0.05)$ than values in the other groups (acidified milk $6.30(0.03)$, 


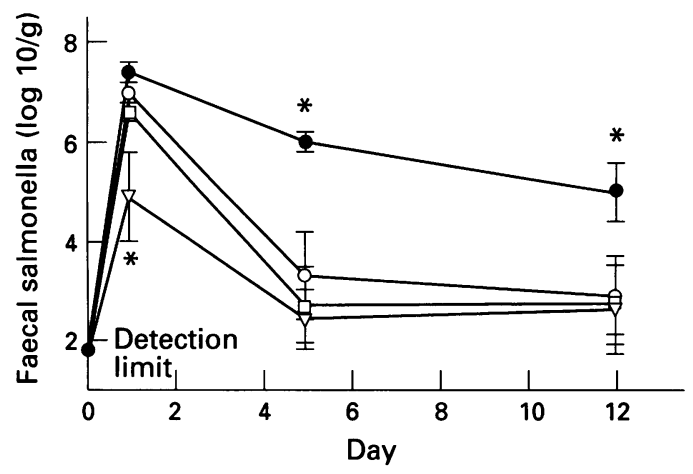

Figure 1: Faecal excretion of salmonella (mean (SEM)) after oral administration of $1 \cdot 10^{9} \mathrm{CFU}$ of this pathogen on day 0. Symbols: $\bigcirc$ low calcium milk, $\bigcirc$ milk, $\square$ acidified milk and $\nabla$ yoghurt. ${ }^{\star}$ Denotes that faecal salmonella excretion of the indicated group is significantly different from all other groups $(p<0.05)$.

milk $6 \cdot 21(0 \cdot 01)$, and low calcium milk $6 \cdot 21$ $(0.05))$. Salmonella infection had no effect on the pH. Before infection, the cytolytic activity of faecal water from the high calcium groups (milk, acidified milk, and yoghurt) did not differ from each other and varied between 10 and $22 \%$ (Fig 2). The cytolytic activity of faecal water of rats fed the low calcium milk was $100 \%$ when the standard assay using $80 \mu \mathrm{l}$ of faecal water was applied. To study whether salmonella infection increased lytic activity any further in this group, erythrocytes were also incubated with a smaller volume $(40 \mu \mathrm{l})$ of faecal water. After salmonella infection, the largest increase in cytolytic activity of faecal water occurred in the group fed the low calcium milk. Rats fed regular milk showed a smaller, but significant, increase. Remarkably, salmonella infection had no significant effect on the lytic activity of faecal water of rats fed acidified milk or yoghurt.

\section{CONCENTRATIONS OF BILE ACIDS, FATTY}

ACIDS, AND IRON IN FAECAL WATER

Compared with the three high calcium groups, the concentration of bile acids in faecal water of rats fed low calcium milk was much higher

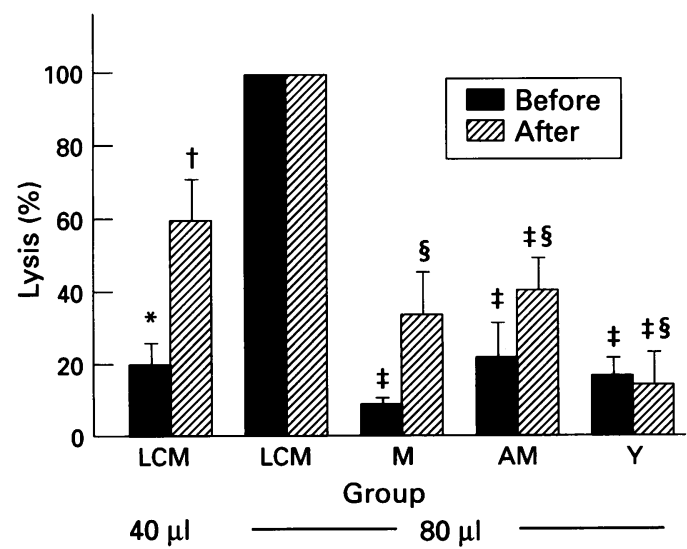

Figure 2: Cytolytic activity of faecal water (mean (SEM)) before and after infection. For all groups $80 \mu \mathrm{l}$ of faecal water was used in the haemolysis assay. To detect the difference in cytolytic activity before and after infection in the low calcium milk group, $40 \mu \mathrm{l}$ of faecal water were also used in the assay for this group. Abbreviations: LCM=low calcium milk, $M=$ milk, $A M=$ acidified milk, and $Y=$ yoghurt. Bars not sharing the same symbol are significantly different from each other $(p<0.05)$. (low calcium milk $2.40(0.17) \mathrm{mM}$, milk 0.77 $(0 \cdot 10) \mathrm{mM}$, acidified milk $1.09(0 \cdot 16) \mathrm{mM}$, yoghurt $0.69 \quad(0.05) \quad \mathrm{mM} \quad(\mathrm{p}<0.05))$. Salmonella infection had no effect on the bile acid concentration in faecal water. Before infection, the mean free fatty acid concentration in faecal water was $0.46(0.10) \mathrm{mM}$ in the low calcium milk group, $0.31(0.03) \mathrm{mM}$ in the milk group, $0.76(0.16) \mathrm{mM}$ in the acidified milk group, and $1.62(0.52) \mathrm{mM}$ in the yoghurt group. The infection had no significant effect on the concentration of free fatty acids in faecal water.

Despite an equal dietary iron intake of about $7 \cdot 7 \mu \mathrm{mol} / \mathrm{d}$, the iron concentration in faecal water of rats fed low calcium milk was at least five times higher than that in faecal water of rats fed the high calcium diets (Fig 3). After infection, soluble iron increased significantly only in the groups fed low calcium milk and normal milk.

APPARENT IRON ABSORPTION AND FAECAL EXCRETION OF MUCIN, ALP, AND PHOSPHATE The apparent iron absorption is calculated by subtracting the faecal iron excretion from the dietary iron intake. As mentioned above, dietary iron intake was about $7 \cdot 7 \mu \mathrm{mol} / \mathrm{d}$ and was not affected by diet or by the infection. Before infection, all groups had an apparent iron absorption of about $2 \cdot 7 \mu \mathrm{mol} / \mathrm{d}$ (Fig 4). After infection, the apparent iron absorption decreased towards zero in rats fed low calcium milk, milk, and acidified milk $(p<0.05)$. The apparent iron absorption in rats fed yoghurt was not significantly altered by the infection. In the period before infection, faecal mucin excretion was significantly raised in rats fed low calcium milk compared with rats fed the high calcium diets (Fig 5, p<0.05). After infection, the mucin excretion increased significantly in all groups. The largest increase was observed in the low calcium milk group, whereas animals fed yoghurt had the smallest increase in faecal mucin excretion after infection.

ALP excretion in faeces did not differ between diet groups before infection (Fig 6). A dramatic, infection induced increase in ALP excretion was noticed in the low calcium milk

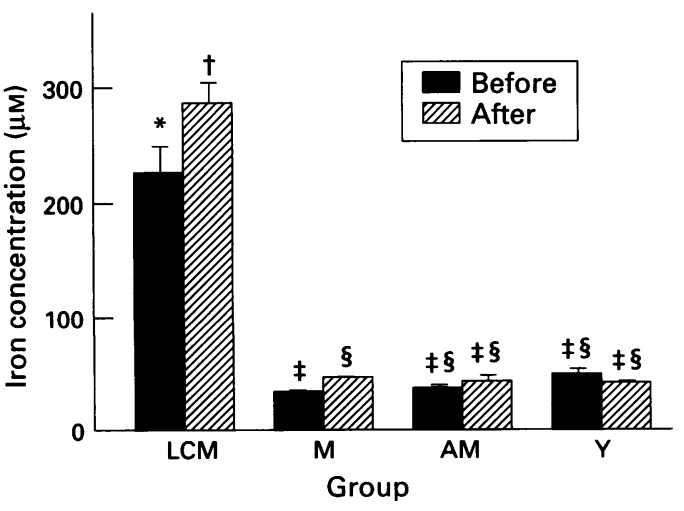

Figure 3: Iron concentration in faecal water (mean (SEM)) before and after infection. Abbreviations: $L C M=$ low calcium milk, $M=$ milk, $A M=$ acidified milk, and $Y=y o g h u r t$. Bars not sharing the same symbol are significantly different from each other $(p<0.05)$. 


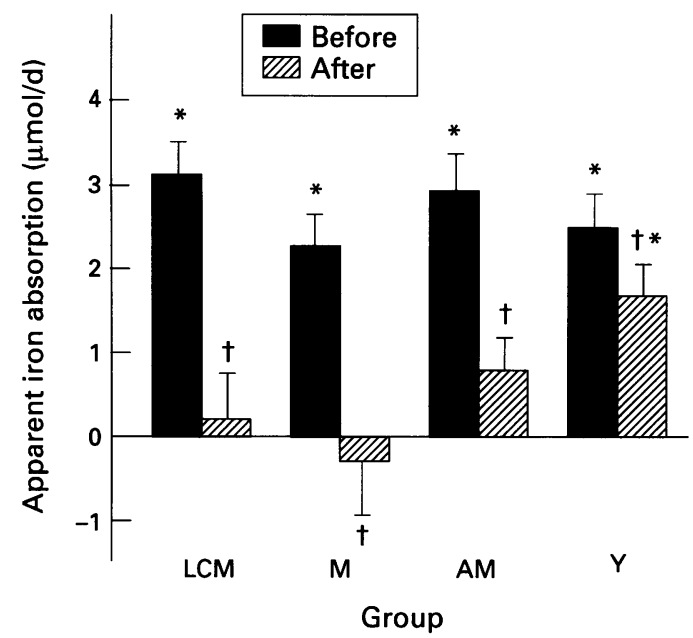

Figure 4: Apparent iron absorption (defined as dietary iron intake minus faecal iron excretion) (mean (SEM)) before and after salmonella infection. Abbreviations: $L C M=$ low calcium milk, $M=$ milk, $A M=$ acidified milk, and $Y=$ yoghurt. Bars not sharing the same symbol are significantly different from each other $(p<0.05)$.

group, and to a lesser extent in the milk group. The groups fed acidified milk and yoghurt showed the smallest increase in faecal ALP excretion.

Despite the equal phosphate content of the diets (mean $112 \mathrm{mmol} / \mathrm{kg}$ dry weight), inorganic phosphate excretion in the faeces of the low calcium milk group was only a fraction of that of the high calcium groups (Table, $p<0.05)$. Except in the acidified milk group, faecal inorganic phosphate excretion increased significantly after salmonella infection. Considering the unchanged food intake after infection, this implies that the phosphate absorption was slightly diminished during salmonellosis.

\section{Discussion}

To our knowledge, this is the first study showing the impact of dietary calcium on the colonisation resistance of rats to salmonella infection. In addition to calcium, fermentation of milk by yoghurt bacteria apparently reinforces considerably the resistance to infection. The first day after administration of salmonella, the rats on the yoghurt diet had a significantly lower faecal salmonella excretion than rats fed the other diets (Fig 1). This might

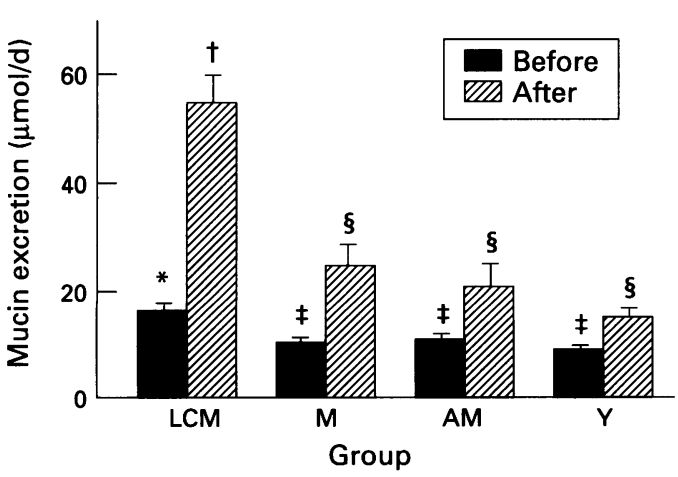

Figure 5: Daily mucin excretion in faeces (mean (SEM)) before and after salmonella infection. Abbreviations: LCM=low calcium milk, $M=$ milk, $A M=$ acidified milk, and $Y=$ yoghurt. Bars not sharing the same symbol are significantly different from each other $(p<0.05)$. reflect an effect of yoghurt on the gastric barrier. Because the gastric emptying rate of yoghurt is half that of milk, ${ }^{7}$ prolonged exposure to gastric acid as well as lactic acid in the yoghurt could have reduced the effective inoculum. In vitro incubation studies at $37^{\circ} \mathrm{C}$ showed that yoghurt was bactericidal to this particular salmonella strain. Within an hour, more than $95 \%$ of the inoculum was killed. In contrast, milk acidified with hydrochloric acid to $\mathrm{pH} 4 \cdot 2$ (the $\mathrm{pH}$ of the yoghurt) did not affect the viability of salmonella, even after six hours' incubation. When incubated in milk or low calcium milk salmonella rapidly multiplied (data not shown). Although dietary effects on the gastric barrier could have influenced faecal salmonella counts the first day after infection, this is not a likely explanation for the faecal Salmonella counts later on in the experiment. ${ }^{3}$ It is reasonable to assume that population levels of salmonella in faeces several days after the infection are determined by the intestinal resistance to this pathogen. The calcium content of the diets strongly influenced the intestinal resistance to this pathogen. On day 5 , salmonella counts in faeces had decreased drastically in rats fed the high calcium diets, whereas those in faeces of rats fed low calcium milk were 1000 times higher. This difference, although less pronounced, was still present at day 12. The persistent high salmonella levels in faeces of rats fed low calcium milk corresponded with a significant reduction in the percentage dry weight of the faeces in this group (Table).

Dietary calcium greatly reduced the cytolytic activity of faecal water before infection (Fig 2). This agrees with previous work from our laboratory. ${ }^{11-14}$ The high luminal cytolytic activity in the low calcium milk group coincided with a reduced colonisation resistance to salmonella. Considering these results, it is tempting to speculate that a high luminal cytolytic activity predisposes to salmonella infection. By lowering the cytolytic activity of luminal contents and reducing epithelial cell damage, ${ }^{11-14}$ the mucosal integrity and resistance to infection might be enhanced. In addition, we have now shown that salmonella infection has a striking effect on the cytolytic activity of faecal water. In

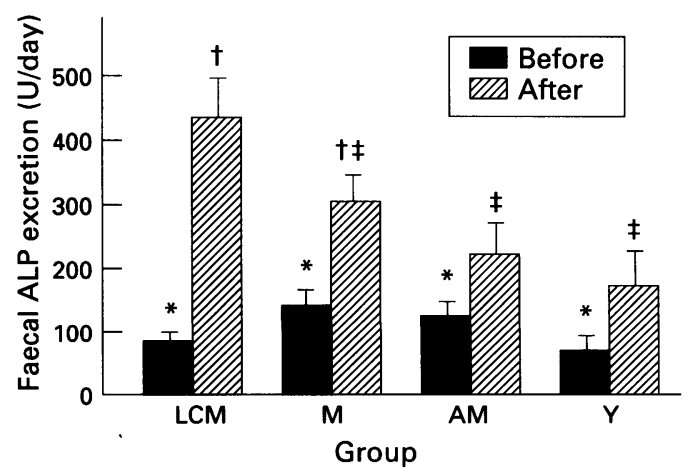

Figure 6: Faecal alkaline phosphatase (ALP) excretion (mean (SEM)) as a marker of intestinal epitheliolysis. Abbreviations: $L C M=$ low calcium milk, $M=$ milk, $A M=$ acidified milk, and $Y=y$ oghurt. Bars not sharing the same symbol are significantly different from each other $(p<0.05)$. 
accordance with high population levels of salmonella in faeces of rats fed low calcium milk, the cytolytic activity of faecal water of this group increased strongly after infection. No significant change could be noticed in rats fed acidified milk or yoghurt. The concentrations of bile acids and fatty acids, important cytolytic surfactants in faecal water, ${ }^{11-14}$ did not rise after infection. This indicates that these surfactants were not responsible for the increase in cytolytic activity after infection. Some salmonella strains seem to be able to produce enterotoxins, but none of these toxins has been shown to play a role in the virulence of this pathogen or the production of symptoms. ${ }^{2526}$ The production of reactive oxygen metabolites or bactericidal proteinases by attracted inflammatory cells (like macrophages) may have contributed to the pathogenesis of infection. Investigations are now being carried out to identify the infection related lytic substances in faecal water.

Soluble iron plays a critical role in inflammatory processes induced by bacterial infections. Firstly, $\mathrm{Fe}^{2+} / \mathrm{Fe}^{3+}$ is an important redox couple in the formation of reactive oxygen metabolites. ${ }^{27}$ Secondly, the bactericidal action of lysosomal proteins of neutrophils is neutralised by excess iron. ${ }^{28}$ Thirdly, iron is an essential nutrient for bacterial growth. ${ }^{28}$ To minimise epithelial cell damage and to maximise the resistance against pathogens, the soluble iron concentration in the intestinal lumen should be kept as low as possible. Our results showed that calcium in milk products strongly reduced the soluble iron concentration in faecal water (Fig 3). The phosphate content of the various diets was not different (mean $112 \mathrm{mmol} / \mathrm{kg}$ dry weight). However, in contrast to the high calcium diets, the rats fed low calcium milk almost completely absorbed the phosphate (Table) because hardly any precipitation with calcium could occur. These results suggest that luminal iron is coprecipitated by a calcium-phosphate complex. The relatively small, but significant, increase in the iron concentration in faecal water after infection in the low calcium milk and milk groups might originate from iron in haemoglobin, due to salmonella induced intestinal bleeding. ${ }^{29}$ Because iron-withholding is a defence system of the host against bacterial infections, ${ }^{30}$ the apparent iron absorption, defined as dietary iron intake minus faecal iron excretion, was quantified. After salmonella infection, the apparent iron absorption had decreased towards zero in the low calcium milk, milk, and acidified milk group (Fig 4). Bezkorovainy also showed that iron absorption in the small intestine was decreased during infections. ${ }^{31}$ Remarkably, in rats fed yoghurt the infection had no significant effect on this parameter.

The mucous lining of the gastrointestinal tract is an important component of the mucosal defence system, forming a physical barrier between potentially harmful bacteria or substances in the lumen and the underlying mucosa. Accelerated mucin secretion occurs in response to a variety of physiological and pathological stimuli, including irritants like oxygen radicals, ${ }^{32}$ bacterial enterotoxins, ${ }^{33}$ and intestinal pathogens. ${ }^{34}$ The present study indicates that mucin secretion correlates with the severity of the infection. Hiraishi et al found that iron enhanced the oxygen radical induced mucin release of cultured mucous producing cells. ${ }^{32}$ This seems very interesting, regarding the high iron concentration in faecal water of rats fed low calcium milk. A significant increase in faecal mucin excretion was already present in the low calcium milk group before infection $(p<0.05)$, possibly as a result of the high bile acid concentration in faecal water in this group and the high luminal cytolytic activity. Increased epithelial cell damage results in an increased cell proliferation to maintain mucosal integrity. ${ }^{11-14}$ The high population levels of salmonella in the faeces of rats fed low calcium milk, accompanied by a notable increase in cytolytic activity of faecal water after infection, resulted in a large increase in epitheliolysis, as measured by faecal ALP excretion $^{11-14}$ (Fig 6). A significant increase in faecal ALP excretion also occurred in the milk group, whereas the acidified milk and yoghurt groups showed the smallest increase after infection. The infection induced increase in epithelial cell turnover agrees with the results of other studies using cellular proliferation markers. ${ }^{35-37}$ Activation of $\mathrm{T}$ lymphocytes ${ }^{38}$ and the release of tumour necrosis factor $\alpha^{35}$ and interleukin $1 \alpha^{36}$ are proposed mediators for the villus atrophy and crypt cell hyperplasia seen in various intestinal infections. ${ }^{39}$

In summary, it can be concluded that calcium in milk products strongly increased the colonisation resistance of rats to salmonella infection. This is accompanied by a reduced infection induced increase in luminal parameters such as cytolytic activity of faecal water, faecal mucin excretion, and intestinal epitheliolysis as measured by faecal ALP excretion. Lowering the luminal cytolytic activity, thereby reducing the epithelial cell damage and enhancing the mucosal integrity, and/or diminishing the availability of iron for pathogen growth seem to be important mechanisms by which calcium exerts its protective effect. Compared with normal milk, fermented milk reinforced the resistance to salmonella infection. Whether these protective luminal effects of calcium and fermented products also improve the immunological defence against salmonella infection is at present not known and requires further investigation.

The authors thank Jacques Bindels (Nutricia, Zoetermeer) for kindly providing Calcinon, Cees Daamen (Gist-brocades, Delft) for providing Maxilact, Anton van den Hoven and Klaas Leffring (Department of Technology) for preparing the milk products, and Maria Peters (Laboratory Animals Center, Wageningen) for expert biotechnical assistance.

1 Sarker SA, Gyr K. Non-immunological defence mechanisms of the gut. Gut 1992; 33: 987-93.

2 Gorden J, Small PLC. Acid resistance in enteric bacteria. Infect Immun 1993; 61: 364-7.

3 Collins FM. Salmonellosis in orally infected specific pathogen-free C57B1 mice. Infect Immun 1972; 5: 191-8.

4 Neal KR, Brij SO, Slack RCB, Hawkey CJ, Logan RFA Recent treatment with $\mathrm{H}_{2}$ antagonists and antibiotics and gastric surgery as risk factors for salmonella infection BMF 1994; 308: 176 .

5 Levant JA, Walsh JH, Isenberg JI. Stimulation of gastric secretion and gastrin release by single oral dosis of calcium carbonate in man. $N$ Engl $\mathcal{F}$ Med 1973; 289: 555-8. 
6 Floor MK, Jahangeer S, d'Ambrosio C, Alabaster O. Serum gastrin increases with increasing dietary calcium but not with increasing dietary fat or fiber in Fischer- 344 rats. $f$ Nutr 1991; 121: 863-8.

7 Mahé S, Marteau P, Huneau JF, Thuillier F, Tomé D. Intestinal nitrogen and electrolyte movements following fermented milk ingestion in man. Br $f$ Nutr 1994; 71: fermented

8 Hara $\mathrm{H}$, Nishikawa $\mathrm{H}$, Kiriyama $S$. Different effects of casein and soybean protein on gastric emptying of protein and small intestinal transit after spontaneous feeding of diets in rats. Br $\mathcal{F}$ Nutr 1992; 68: 59-66.

9 Eastwood MA. The physiological effect of dietary fiber: an update. Annu Rev Nutr 1992; 12: 19-35.

10 Cabotaje LM, Shinnick FL, Lopéz-Guisa JM, Marlett JA Mucin secretion in germfree rats fed fibre-free and psyllium diets and bacterial mass and carbohydrate fermentation after colonization. Appl Environ Microbiol 1994; 60: 1302-7.

11 Lapré JA, De Vries HT, Van der Meer R. Cytotoxicity of fecal water is dependent on the type of dietary far and is reduced by supplemental calcium phosphate in rats. $\mathcal{F}$ Nutr 1993; 123: 578-85.

12 Govers MJAP, Termont DSML, Van der Meer $R$ Mechanism of the antiproliferative effect of milk mineral and other calcium supplements on colonic epithelium. Cancer Res 1994; 54: 95-100.

13 Lapré JA, De Vries HT, Koeman JH, Van der Meer R. The antiproliferative effect of dietary calcium on colonic epithelium is mediated by luminal surfactants and dependent on the type of dietary fat. Cancer Res 1993; 53: 784-9.

14 Lapré JA, De Vries HT, Termont DSML, Kleibeuker JH, De Vries EGE, Van der Meer R. Mechanism of the protective effect of supplemental dietary calcium on cytolytic tective effect of supplemental dietary calcium on cytoly

15 Van Riel JAM, Olieman C. High-performance liquid chromatography of sugars on a mixed cation-exchange resin column. Fournal of Chromatography 1986; 362: 235-42.

16 American Institute of Nutrition. Report of the American Institute of Nutrition ad hoc committee on standards for nutritional studies. $\mathcal{F}$ Nutr 1977 ; 107: 1340-8.

17 Rampling A. Salmonella enteritidis five years on. Lancet 1993; 342: 317-8.

18 Oudenhoven IMJ, Klaasen HLBM, Lapré JA, Weerkamp AH, Van der Meer R. Nitric oxide-derived urinary nitrate as a marker of intestinal bacterial translocation in rats. Gastroenterology 1994; 107: 47-53.

19 Giaffer MH, Holdsworth CD, Duerden BI. The assessment of faecal flora in patients with inflammatory bowel disease of faecal flora in patients with inflammatory bowel disease
by a simplified bacteriological technique. $\mathcal{f}$ Med Microbiol by a simplified bacter

20 Fiske $\mathbf{C H}$, Subbarow Y. The colorimetric determination of phosphorus. $₹$ Biol Chem 1925; 66: 375-400.

21 Van der Meer R, De Vries HT, Glatz JFC. t-Butanol extraction of feces: a rapid procedure for enzymatic determination of fecal bile acids. In: Beynen AC, Geelen MJH, Katan MB, Schouten JA, eds. Cholesterol metabolism in health and disease. Wageningen: Ponsen \& Looyen, 1985: 113-9.

22 Mashige $\mathrm{F}$, Imai $\mathrm{K}$, Osuga $\mathrm{T}$. A simple and sensitive assay of total serum bile acids. Clin Chim Acta 1976; 70: 79-86

23 Crowther RS, Wetmore RF. Fluorimetric assay of O-linked glycoproteins by reaction with 2-cyanoacetamide. Anal glycoproteins by reaction
Biochem 1987; 163: $170-4$.

24 Lapré JA, Termont DSML, Groen AK, Van der Meer R. Lytic effects of mixed micelles of fatty acids and bile acids. Am f Physiol 1992; 263: G333-7.

25 Salyers AA, Whitt DD. Salmonella infections. In: Bacterial pathogenesis: a molecular approach. Washington: ASM Press, 1994: 229-43.

26 Mims CA. Mechanisms of cell and tissue damage. In: The pathogenesis of infectious disease. 3rd ed. New York: Academic Press, 1991: 179-225.

27 Cohen MS. Molecular events in the activation of human neutrophils for microbial killing. Clin Infect Dis 1994; 18: S170-9.

28 Kent S, Weinberg ED, Stuart-Macadam P. The etiology of the anemia of chronic disease and infection. $f$ Clin Epidemiol 1994; 47: 23-33.

29 Cariani G, Vandelli A. Salmonellosis-induced hemorrhage and ulcerations of the colon. Endoscopy 1993; 25: 488 .

30 Weinberg ED. The iron-withholding defense system. ASM News 1993; 59: 559-62.

31 Bezkorovainy A. Biochemistry of nonheme iron in man. Clin Physiol Biochem 1989; 7: 1-17.

32 Hiraishi $H$, Terano A, Ota $S$, Mutoh $H$, Sugimoto $T$, Razandi $M$, et al. Oxygen metabolites stimulate mucous glycoprotein secretion from cultured rat gastric mucous cells. Am 7 Physiol 1991; 261: G662-8.

33 Roomi N, Laburthe M, Fleming N, Crowther R, Forstner J. Cholera-induced mucin secretion from rat intestine: lack Cholera-induced mucin secretion from rat intestine: lack of effect of cAMP, cycloheximide,

34 Mantle M, Thakore E, Hardin J, Gall DG. Effect of Yersinia enterocolitica on intestinal mucin secretion. $A m \mathcal{F}$ Physiol 1989; 256: G319-27.

35 Arnold JW, Klimpel GR, Niesel DW. Tumor necrosis factor $(\mathrm{TNF} \alpha)$ regulates intestinal mucus production during salmonellosis. Cell Immunol 1993; 151: 336-44.

36 Rafferty JF, Noguchi Y, Fischer JE, Hasselgren PO. Sepsis in rats stimulates cellular proliferation in the mucosa of the small intestine. Gastroenterology 1994; 107: 121-7.

37 Wang JY, Johnson LR, Tsai YH, Castro GA. Mucosal ornithine decarboxylase, polyamines, and hyperplasia in ornithine decarboxylase, polyamines, and hyperplasia

38 MacDonald TT, Spencer J. Evidence that activated mucosal $T$ cells play a role in the pathogenesis of enteropathy in human small intestine. $\mathcal{F}$ Exp Med 1988; 167: 1341-9.

39 Powell DW. New paradigms for the pathophysiology of infectious diarrhoea. Gastroenterology 1994; 106: 1705-7. 